\title{
FATE OF RABBIT EGGS FERTILIZED IN THE UTERUS
}

\author{
R. H. GLASS \\ Department of Obstetrics and Gynecology, Yale University School of Medicine, \\ 333 Cedar Street, New Haven, Connecticut 06510, U.S.A.
}

(Received 24th March 1972, accepted 4th May 1972)

Rabbit eggs can be fertilized in the uterus but their subsequent development in this organ is limited. Bedford (1970) transferred newly ovulated eggs to the uterus of does mated 12 to $13 \mathrm{hr}$ earlier and found that $94 \%$ of the recovered eggs had been fertilized when they were examined 6 to $7 \mathrm{hr}$ later. Under similar conditions, Chang (1955) found the majority of eggs at the pronuclear stage, but some of these fertilized eggs recovered $6 \mathrm{hr}$ after deposition in the uterus had begun to degenerate. The deleterious effects of the uterine environment may result in rapid destruction of the newly fertilized egg. Despite occlusion of the uterocervical junction, Adams (1970) was able to recover only $53 \%$ of eggs that had been transferred to the uterus $4 \mathrm{hr}$ earlier.

Fertilization in the uterus can, however, be compatible with full development. Thirty-eight per cent of eggs fertilized in the uterus and recovered very soon thereafter developed to full term following transfer to the Fallopian tube of unmated recipients (Adams, 1970). The exact timing of recovery was not specified.

The present report details the effects of uterine fertilization and uterine incubation for specified times on the subsequent development of the egg when transferred to a pseudopregnant recipient or when transferred to culture media.

Unfertilized ova were recovered from donor New Zealand white rabbits which had received 50 i.u. HCG (APL, Ayerst) 12 to $13 \mathrm{hr}$ previously, by flushing the excised Fallopian tubes with culture medium (acidic saline containing $0.25 \%$ glucose and $20 \%$ rabbit serum). Recipient does were mated with fertile bucks 16 to $18 \mathrm{hr}$ before egg transfer.

At the time of transfer, a ligature was placed at the uterocervical junction. A second ligature was placed but not tied around the uterus $1 \mathrm{~cm}$ from the uterotubal junction. The eggs were transferred by means of a Pasteur pipette which was inserted through a small incision in the uterine wall near the uterotubal junction. The eggs were expelled past the second ligature which was then tied as the pipette was withdrawn. A single suture was used to close the uterine incision. More recently, the pipette has been inserted bluntly without benefit of an incision and this has become the preferred method.

The recipient was killed either $3 \mathrm{hr}$ (thirteen does) or $6 \mathrm{hr}$ (seven does) after transfer. The uterus was excised and subsequent manipulations were performed at $37^{\circ}$ C. For recovery of eggs, culture medium was injected through the uterine wall near the uterotubal junction. When the uterus was slightly dis- 
tended, the cervical ligature was cut and the uterine contents allowed to flow out into a watch glass. The eggs were examined under a dissecting microscope for evidence of pronuclear formation before rejecting any eggs that appeared abnormal. A portion of the normal appearing and/or fertilized eggs were transferred to the Fallopian tubes of second recipients that had been mated with vasectomized bucks 12 to $13 \mathrm{hr}$ earlier. Three to six eggs were placed in each tube. The recipients also received 50 i.u. HCG at the time of mating. Thirteen to 14 days after transfer, these animals were examined at autopsy for evidence of implantation sites. As a control for the transfer technique, eggs recovered from the oviduct $18 \mathrm{hr}$ after mating were transferred to the Fallopian tubes of synchronous pseudopregnant does. These animals were examined 13 to 14 days later for implantation sites.

A second group of normal appearing or fertilized eggs were transferred from the uterus to dishes containing $4 \mathrm{ml}$ culture medium and were incubated at $37^{\circ} \mathrm{C}$ in air under paraffin oil (Fraser, Dandekar \& Vaidya, 1971). The dishes were examined for cleaved embryos $24 \mathrm{hr}$ later.

Three hours after transfer to the uterus, 69 of 128 eggs (54\%) were recovered. Thirty-four were then transferred to the Fallopian tubes of second recipients. Thirteen to 14 days later, there were eight normal and three resorbing implants.

Thirty-three eggs recovered after $3 \mathrm{hr}$ in the uterus were transferred to culture medium. Following $24 \mathrm{hr}$ in culture, twenty-nine $(87 \%)$ were cleaved, with the greatest number at the four-cell stage.

Forty-seven per cent (53/113) of eggs were recovered following a 6-hr incubation in the uterus. Thirteen of these eggs transferred to the Fallopian tubes of second recipients produced only two resorbing implants when examined 13 to 14 days later. Of thirty-seven eggs placed in culture, sixteen (43\%) had cleaved at the end of $24 \mathrm{hr}$. Fifteen of the cleaved eggs came from one animal which also had supplied the eggs for the two resorbing implants. Eggs from the other six does produced no implants and only one two-cell egg in culture.

When eggs newly fertilized in the oviduct were transferred to the Fallopian tube of synchronous pseudopregnant recipients, 44\% (37/84) produced implants.

While there have been reports of successful pregnancies in women following implantation of an ovary into the uterus (Estes, 1924), this has not been duplicated in animals. Hunter (1968) transferred newly ovulated eggs to the uterus of mated hamsters and was unable to find evidence of sperm penetration 2 to $8 \mathrm{hr}$ later. Fertilization can occur in the rabbit uterus but subsequent development is dependent on transferring the egg to the more hospitable climate of the Fallopian tube. This transfer must be accomplished before $6 \mathrm{hr}$ residence in the uterus. Even a short exposure may be disastrous for a sizeable number of eggs. After only $3 \mathrm{hr}$ in the uterus, approximately $50 \%$ of the eggs are no longer recoverable. This rapid loss suggests the presence of uterine factors inimical to the egg rather than an absence of factors vital for development.

As demonstrated by Chang (1950), the early pseudopregnant uterus is also hostile to eggs newly fertilized in the Fallopian tube. This provides evidence that failure of egg development after fertilization and incubation in the uterus is not due solely to the site of fertilization. 
This study was supported by a grant from the Ford Foundation. My thanks are due to Mrs Ellen Ebersole and Miss Joanna D'Amico for their technical assistance.

\section{REFERENGES}

AdAMs, C. E. (1970) Egg-uterus interrelationships. In: Advances in the Biosciences, Vol. 4, p. 149. Ed. G. Raspé. Pergamon Press, London.

BEDPORD, J. M. (1970) The influence of oestrogen and progesterone on sperm capacitation in the reproductive tract of the female rabbit. F. Endocr. 46, 191.

Chang, M. C. (1950) Development and fate of transferred rabbit ova or blastocyst in relation to the ovulation time of recipients. J. exp. Zool. 114, 197.

Chang, M. C. (1955) Développement de la capacité fertilisatrice des spermatozoides du lapin á l'interieur du tractus génital femelle, et fécond abilité des oeuf de lapine. In: La Function Tubaire et ses Troubles, p. 40. Masson, Paris.

Estes, W. L., JR (1924) Ovarian implantation. Surg. Gynec. Obstet. 38, 394.

Fraser, L. R., Dandekar, P. V. \& VaIdYa, R. A. (1971) In vitro fertilization of tubal rabbit ova partially or totally denuded of follicular cells. Biol. Reprod. 4, 229.

HunTer, R. H. F. (1968) Attempted fertilization of hamster eggs following transplantation into the uterus. F. exp. Zool. 168, 511 . 